\title{
BJ $\mathrm{O} \& \mathrm{PM}$
}

\section{NEW TECHNOLOGIES ADOPTION: A DIGITAL TV STUDY}

\author{
Ronaldo Alípio da Costa Piloto ; José Roberto Ribas ${ }^{b}$; José Luiz Trintac; Joyce Gonçalves Altaf ${ }^{\text {d; }}$ Irene Raguenete \\ Troccolie $^{\mathrm{A}}$ \\ ${ }^{a}$ Veiga de Almeida University (UVA) - Rio de Janeiro, RJ, Brazil \\ ${ }^{b}$ Federal University of Rio de Janeiro (UFRJ) - Rio de Janeiro, RJ, Brazil \\ ' IBMEC - Rio de Janeiro, RJ, Brazil \\ ${ }^{d}$ Faculdades Integradas do Instituto Vianna Júnior - Juiz de Fora, MG, Brasil \\ d Pontifical Catholic University of Rio de Janeiro (PUC-Rio) - Rio de Janeiro, RJ, Brazil
}

\section{Abstract}

This paper reports on the role of socio-demographic and psychographic basis - the later achieved through the Value and Life Styles-2, or VALS-2 - as predictor of the consumers' intention to migrate from the conventional analogical to digital TV broadcast. By means of validation, the sample was split in two groups, one used to estimate the logistic regression coefficients and the other used to confirm the model results and specification. It was observed that, among the alternatives of specification, the psychographic variable VALS-2 First Level and the demographic variables Age and Household Income provided a significant contribution on the discrimination of two segments - early adopters and non-adopters. The research concluded on the importance of using both demographic and psychographic segmentation basis in an integrated manner in order to research the attributes of consumers who declare their positive of migrating to innovating goods.

Keywords: Digital television; Segmentation; VALS-2; Early adoption; Personal values.

\section{INTRODUCTION}

Television reaches viewers in two ways: open and closed. The first one is characterized by free programming transmitted mostly by the air. Any television, if properly installed, can access the programming transmitted by broadcast television. The closed television, also called pay TV, has limited its transmission to subscribers who pay for this service, and one of the technologies that it offers is the transmission system called Direct to Home (DTH). Allowing significant increase in the number of channels and improved image sharpness, DTH was launched in Brazil in the second half of the first decade of the 2000s, pointing a new phase in home entertainment technology in Brazil: a digital and interactive era.

This phenomenon shows that, being a product of technology, television is subject to the advancements of science and modernity, as well as to the competition from other medias. Since the beginning of this century, Brown (2004) pointed out that, when it comes to technology, the third generation in mobile devices, called $3 \mathrm{G}$, and traditional access to the Internet by personal computers and communication channels threaten the supremacy of television. This happens because the two characteristics together - availability and cost - gave them advantage over other ways as well as a direct communication with the receiver. Not coincidentally, Hoineff (2001) pointed out that the death of the old and the birth of the new television was due to new technologies revolution in signal distribution and development of digitization processes.

Digital TV allows the viewer the opportunity to interact with the content displayed on television by giving it, at their discretion, stop transmitting to search more information, such as prices for different models of the watch used by certain actor in a drama, and even make a purchase in real time (Wade et Mckechnie, 1999). With its implementation, the most important way of communication in Brazil seemed to enforce the use of interactivity and individualization of content as essential for communication companies' strategy, as it allows the relationship between advertising and audience beyond the limits. Television now provides the ability to sell directly to the viewer without the need of other tools - such as the telephone or the internet - to provide additional information for the achievement of 
product sales, or to hire a service (Picard, 2004; Cauberghe et Pelsmacker, 2006; Malik, 2008; Chorianopoulos, 2008).

In this environment, studies conducted at the beginning of this century already indicated that manufacturers would face a gradual reduction in the life cycle of products and consumers suffer the pressure of the update due to constant innovation (Waarts et al., 2002; Montaguti et al., 2002).

Not surprisingly more than 10 years ago Moreau, Lehmann et Marman (2001) indicated that this situation would require a perfect identification of segments achieved by innovation, through the evaluation of the factors affecting the early adoption process, creating a more effective marketing strategy. However, the study of the propensity to adopt innovative technologies previously (Atkin et al., 1998; La Rose et Atkin, 1998) had indicated that just an identification of demographic characteristic of consumers would not be enough for this, necessitating inclusion of other factors, like the attitudinal determinants (Marez et al., 2007), the ownership of telecommunications equipment (Dupagne, 2006), interest in alternative media (Atkin et al.,, 2003), or the influence of externalities - such as changes in programming and interaction possibilities (Gupta et al.,, 1999).

Thus, this research found, when the introduction of digital TV in the state of Rio de Janeiro, Brazil, what were the particular socio-demographic and psychographic features that allowed the distinguishing among different consumers, that belongs to a sample composed by teachers and students, collected at two campus of a Brazilian university, those who had a higher intention to migrate to digital TV.

\section{LITERATURE REVIEW}

\subsection{Personal Values}

Rokeach $(1973$, p.5) states that "A value is a strong belief that a specific way of conduct or state of existence is personally or socially preferable to an opposite or inverse way of conduct or state of existence." Also, according to Rokeach (1973), there are two kinds of values: instrumental and terminal. The first indicates if the consumer behavior is aligned with the intended result from an action, while the second incorporates the states desired by consumers as life conduction. For instance, an individual who has, as a terminal value, "a sense of accomplishment," may seek a review of his conduct with instrumental values, such as being "intellectual, honest, responsible, imaginative," among others, depending on their environment and your life experience.
Sheth et al.,(2001) go further, noting that a person, to think about what is important in your life, do it through your personal values, which express the goals that motivate and appropriate ways to achieve these goals. These authors describe values as representations of consumer beliefs about life and acceptable behaviors, but unlike attitudes, these values transcend situations or events and are more durable because they are linked to the structure of the individual's personality. In this case, the values represent the three universals prerequisites of human existence: biological needs, the needs of social interaction and the demands of survival and functionality of the social group to which the individual belongs. Kamamura et Novak (1992) points out that values determine attitudes and behaviors, having said that some values have dominant role in guiding the consumer. This means that, although all values can be identified and detailed, but a few will be crucial in guiding consumer behavior (Leung, 1998). This situation points to the need to study and measure which of the different values present in the consumer are the most important and determinant of their behavior.

Schwartz (1994) argued that structure is made up of ten motivational antecedents which, being strongly correlated with each other; should be observed as a whole or through higher dimensions of order, defined as self-transcendence, conservation, self-promotion and openness to shift. Port et Tamayo (2007) evaluated the relationship between two value structures and general labor, from the scale of values of Schwartz (1994). The associations were identified as : (1) openness to change and professional achievement, (2) social relations and self-transcendence, (3) prestige and self-promotion, (4) conservation and stability. Tamayo (2007) proposed yet, hierarchy transcultural values of fiftysix, plus four values characteristic of Brazilian culture: work (considered as a supreme value), dreamer, vanity and smartness. The same author proposed ten motivational values: self-determination, benevolence, philanthropy, selfrealization, hedonism, conformity, security, stimulation, tradition and power. Kahle (1983) proposed a scale called List of Values, or LOV, which comes from studies in applied research related to consumption (Homer et Kahle, 1988; Kahle et al., 1986). The LOV is a measuring instrument that has a reduced amount of just nine terminal values: self-respect, self-fulfillment, security, sense of belonging, encouragement, sense of accomplishment, fun, be respected and warm relationships with others.

\subsection{Values and Lifestyle (VALS)}

The Values and Lifestyle System (VALS), and its new revised and modified, the VALS-2, are instruments of psychographic segmentation. 
According to Holman (1984), VALS is a typology for American consumers, although the Stanford Research Institute (SRI) comes studying the possibility of extending this technique to other cultures. Based on the theoretical hierarchy of needs and the concept of social character, its purpose, according to Kahle et al., (1986), is to bring up and investigate the individual values. This objective is achieved by identifying current and future opportunities from customer segmentation based on personality traces that define the behavior of these customers. The VALS methodology was developed by survey research, which allowed to identify demographic and psychological characteristics that affect consumer behavior and their preferences and decisions regarding the activities, the consumption of products, services and media. Its application is aimed at understanding the reasons that lead consumers to realize their choices, or the motivations that encourage the consumer to decide to purchase a product.

For Sheth et al., (2001), although the technique has attempted to identify differences in the consumption of products between the various segments, its best use is in the orientation of Marketing Communications, through the representation of lifestyles and values that companies seek to identify and to reach. Derived from this methodology, the VALS-2 covers the assets and capabilities psychological, physical, demographic and materials. This is an improvement that occurred based on the argument that it would be possible to improve our understanding of consumer behavior if the methodology was more related to lifestyle indicators (Solomon, 2002). In this case, indicators of study level, income, self-confidence, health, intelligence and disposition were specifically designed to measure consumer behavior patterns. This is done by means of 39 questions, 35 were aligned to the psychological factors and 4 to the demographic factors, the answers vary on a continuum between minimum and plentiful.

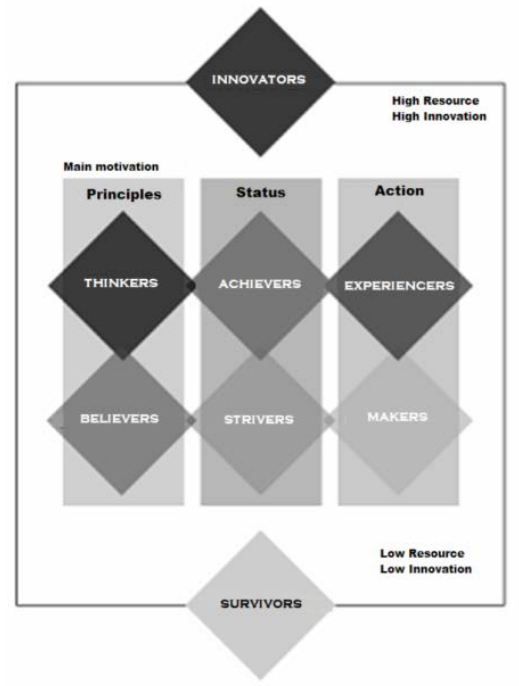

Figure 1 -VALS-2 Typology Diagram Source: Adapted from Veiga-Neto (1997)

\section{METHODOLOGY}

Thereafter, the respondent is classified into one of eight groups - based on the resources it has and its self-orientation - can be guided by three self-orientation (see Figure 1): 1. Principle - when determining their choices by criteria idealized and abstract 2 . Status - when they buy products and services that represent your success against others, 3. Action - when they are guided by a desire for social or physical activity, variety and risk.

The sample was composed by students and teachers economically active of two university campuses located in the cities of Rio de Janeiro and Niteroi, belonging to a Brazilian private university. They recognized the existence of digital television technology, but not necessarily identify their characteristics or differences with the analog system. The population size was estimated at eight hundred students and two hundred teachers, and the survey was conducted in late October 2007, by which time two stations provide what, to its subscribers in the state of Rio de Janeiro, the ability to migrate to digital TV by through the transmission system called DTH.

A previous test was conducted in order to assess the adequacy of an initial questionnaire as a measurement instrument, and to check the composition of qualitative and quantitative questions extract of Sheth et al., (2001). For this step thirty-one subjects were selected obeying a random criteria and systematic, extracted by the registration number. The tabulation and analysis of results were the basis for the selection and the appropriateness of questions.

The final survey was submitted to a new sample of eightytwo students and thirty-nine teachers, selected according to criteria similar to the previous step. The interviews took place by direct approach and were held on the premises of the two campuses during the period from the first week of September and the last week of October 2007, during the daytime, from Monday to Friday. The identification of viable subjects in the sample came from two-filter issues at first contact made by phone.

The predictive variables VALS psychographic- 2 at First Degree and VALS-2 in the Second Degree were obtained as follows: (a) the respondent was asked to complete a survey containing thirty-nine questions derived from the form available on the website of SRI (2007), and whose family income ranges were converted to U.S. dollars at the exchange rate of U.S. dollar prevailing at the date of search; (b) the answers given by the interviewee were inserted in the black box program available on the same site, obtaining thus the ratings VALS-2 for the two levels; (c) these were converted from nominal to ordinal scale, in ascending order by the resources and self-direction, where: $1=$ survivors, 2 = makers, $3=$ strivers, $4=$ believers, $5=$ experiencers; $6=$ achievers, $7=$ thinkers and $8=$ innovators. 
The predictor demographic variables were Gender, Age Group, Economy, Family Family Income and Level of Instruction. The age groups and economic classes were established as Brazil Criterion (ABEP, 2007).The variable Knowledge of Digital TV has been established with binary scale. In this case, " 1 " was assigned to those who were able to identify or describe its benefits over analog TV and " 0 " for otherwise. The dependent variable Intention Migration to Digital TV was specified from a binary scale, having been assigned " 0 " for negative intent and " 1 " for a positive intention.

\section{HYPOTHESES}

According to Clark et Goldsmith (2006), the personality characteristics of the consumers determine the spontaneity of his/her attitude of early adoption. The authors tested a model containing three constructs: the innovative aspect of the subject; their susceptibility to interpersonal influence, reflected by attention to information that enables social comparison and self-monitoring, and relaxed his role, defined by Kahle (1995a, 1995b) as kind of guy less affected by social interference, more utilitarian and less attention to superficial aspects. Such studies demonstrate the theoretical concern with psychographic aspects of adopters of innovative products.

Thus, (a) knowing that both - Lifestyle first level and second level Lifestyles - are associated with an ordinal scale ranging from " 1 " for the survivor to " 8 " for the subject innovator, and (b) established that the dichotomous variable Intent Migration to digital TV shows " 0 " for unfavorable, and " 1 " for favorable, we have the following assumptions:

H1: The psychographic profile of the first level has a direct relationship with the intention to migrate to digital TV;

$\mathrm{H} 2$ : The psychographic profile of the second level has a direct relationship with the intention to migrate to digital TV.

The importance of socio-demographic segmentation bases between subjects with intent to early adoption of innovative technologies was studied by Zeithaml et Gilly (1987), by Gauvin et Sinha (1993), and by Lee et al., (2003). Understanding who makes the buying decisions is an important issue for marketers, since they need to determine whom to approach, and if they need to achieve both genders or specifically one - male or female. It has been given special attention which spouse plays the role of what has been called the family financial authority. According to Solomon (2000), it is the individual who accompanies the family accounts and who decides how any additional resources will be spent. Although no evidence has been found in other studies that gender is a demographic variable representative for the categorical variable where the male is equal to " 0 " and the female equal to " 1 " that will be tested:
H3: The gender has a relationship with the intention to migrate to digital TV, which is: (a) reverse when the gender predominant in favorable intention for male and (b) direct when the gender predominant in favorable intention is female.

Researches by Mathur et al., (2006), by Gilly et Zeithaml (1985), by Zeithaml and Gilly (1987) et by Strutton et al., (1994) concluded that age influences the intention of the early adoption of new technologies, whereas older people tend to have low probability of demonstrating a positive attitude. Simcok et al., (2006) pointed out, however, that despite having found evidence of a direct relationship between age groups and risk rejection, it is necessary to adopt more sophisticated segmentation techniques. Once the Ages is an ordinal variable with intervals of " 1 " for ages 18 to 24 years until "7" over the age of 65 , place up the hypothesis that older people are more reluctant to migration:

$\mathrm{H} 4$ : The age has an inverse relationship with the intention to migrate to digital TV.

Mavri et Ioannou (2006), El-Haddad et Almahmeed (1992) et Zeithaml et Gilly (1985) found that subjects with higher income, belonging to higher social extract and welleducated, tend to be more susceptible to be beginners to adopt new technologies. As the social extract an ordinal variable ranging from " 1 " to the lower class and to " 5 " for the class $\mathrm{A} 1$ higher:

H5: The extract in which the subject is classified has a direct relationship with the intention to migrate to digital TV.

As the range of Family Income an ordinal variable where "1" represents income less than four minimum wages to " 10 ", meaning an income exceeding eighty times the minimum wage:

H6: The family income has a direct relationship with the intention to migrate to digital TV.

For Level Instruction, where " 1 " entry-level to " 6 " for the guy who holds postgraduate course:

H7: The level of education has a direct relationship with the intention to migrate to digital TV.

Similarly to the findings obtained by Mavri et loannou (2006), as for the cognitive aspect it was evaluated whether the level of information that the subject had about the digital television was representative in their purchase intent, which is a categorical variable where " 0 "represents" being misinformed "and" 1 "represents the opposite. then:

H8: The Knowledge of Digital TV, manifested by the subject, has a direct relationship with the intention to migrate to it. 


\section{RESULTS}

A binary logistic regression is adopted to verify the occurrence of a phenomenon that differentiates two classes, one favorable to the occurrence of the phenomenon and other antagonistic or unfavorable. The dependent variable is categorical, assuming binary values, and the dependent variables are metric or also categorical.

For his feature continuous, the estimate of the dependent variable may result in probability estimate, to do this, is required a transformation exponential. To be a continuous dependent variable called the Migration Propensity for Digital TV referenced by TVD.

In this case, for larger values of TVD also the higher the chances that the research subject acceding to digital TV. In logistic regression, the relationship between DTV and probability $\pi[D T V]$ that such action will occur is described in the function:

$$
\pi[T V D] i=\frac{e^{T V D i}}{1+e^{T V D i}}
$$

The model assumes that TVD is linearly dependent on the following predictor variables.

TVDi $=b o+b 1 . V A L S 2[1] i+b 2 . V A L S 2[2] i+b 3 . G E N i+$ $b 4 . A G E+b 5 . S O C i+b 6 . I N C O M E+b 7 . I N S T R i+b 8 . K N O i$

The objective of the procedure is to discriminate the tendency to migration of individuals from their psychographic characteristics, socio-demographic and cognitive, thus identifying those who have the propensity to adopt digital television. Among the one hundred twenty-two subjects in the sample studied, eighty-two were randomly selected in order to build a logistic regression model, while the remaining thirty-nine subjects were reserved to assist in validating the model. As a characteristic for the tendency to migrate to digital TV, two thirds of the sample were favorable of migration. In the validation sample, $49 \%$ of participants declared to be favorable. The model specification was obtained by gradual stepwise refinement technique of forecasting model by likelihood ratio (LR). For logistic regression, we used SPSS version 12.0. The variables were included one by one from the degree of additional contribution in explaining the response variable, being selected by the magnitudes of their scores and blocked when the significance of the contribution exceeded $5 \%$. The null model (no predictor variable) showed Wald statistic equal to 9.168 .

The resulting model presents, in Table 1, the response variable Propensity Migration to Digital TV as dependent on three predictor variables - Lifestyle first level, Age Group (age) range and Household Income (income).
Table 1 - Parameters and significances of the variables included in the model

\begin{tabular}{|l|c|c|c|c|c|}
\hline Variables & Parameter & St.Error & Wald & Sig. & Exp(Param) \\
\hline $\begin{array}{l}\text { Lifestyle } \\
\text { first level }\end{array}$ & 0,824 & 0,339 & 5,908 & 0,015 & 2,279 \\
\hline Age & $-0,988$ & 0,312 & 10,010 & 0,002 & 2,687 \\
\hline Income & 0,636 & 0,263 & 5,872 & 0,015 & 0,529 \\
\hline Intercepto & 6,599 & 2,358 & 7,836 & 0,005 & 0,001 \\
\hline
\end{tabular}

Source: Authors

The ordinal variable Lifestyle first level has a parameter with a positive sign, essential to confirm the hypothesis $\mathrm{H} 1$ that this construct directly affects TVD. The scale begins with 1 and 2 for consumers classified as "survivors" and "makers", which are conservative and averse to change, and develops until 7:08, for those consumers "thinkers" and "innovators" perceived as more likely to change. Since the categorical variable Propensity to Digital TV Migration to assume " 0 " for the consumer reticent and " 1 " for those more inclined, as it moves along the ordinal scale VALS2, conservative style toward innovative, probability $\pi$ [DTV] to TVD equal to " 1 " to accept the migration to digital TV increases in the same way. Making an analysis of sensitivity of the parameter to VALS2 [1], supposing that the probability that a consumer "thinker" will migrate to the digital system is $23 \%$, obtained by estimation from the sample, has, then the chances are for a 3.35:

$$
\text { Migration chance ratio }\{\mathrm{VALS}[1]=2\}=\frac{0,23}{1-0,23}=\frac{1}{3,35}
$$

In this case, the probability of a subject classified as "experiencer" eventually migrates to digital TV increases to $40.5 \%$, this trend confirms the hypothesis accepts:

$$
\pi[\mathrm{TVD}]_{\text {VALS }[1]=3}=\frac{(1 / 3,35) \times 2,279}{1+(1 / 3,35) \times 2,279}=0,4050
$$

The ordinal variable Age Group presented a parameter with a negative signal. This indicates that, since older subjects were interviewed, they showed greater resistance to migrate to the digital TV. This finding demonstrated the same way, an understandable caution that older people exhibit to engage in innovations of the digital society, thereby confirming the hypothesis $\mathrm{H} 4$. The same sensitivity analysis can be developed for the variable age. Inferring analogously, assuming that individuals aged between 25 and 29 years presenting to a probability equivalent one to three to not migrate to digital TV, also estimated from the sample, the odds are: 


$$
\text { Not Migration ratio }\{\mathrm{AGE}=2\}=\frac{0,33}{1-0,33}=\frac{1}{2}
$$

The probability that a subject situated between the ages 30 and 34 will not migrate to digital TV increases to $57.3 \%$, confirming the hypothesis accepts:

$$
\pi[\mathrm{TVD}]_{\mathrm{AGE}=3}=\frac{(1 / 2) \times 2,687}{1+(1 / 2) \times 2,687}=0,5733
$$

The positive sign of the parameter range ordinal variable Family Income H6 confirmed the hypothesis that the possibility of migration to digital TV increases as the subject moves into higher income.

Once this decision involves monetary sacrifice, their impact is mitigated as they have less budget constraints. As a sensitivity analysis, reasoning by analogy, imagine that the probability of a subject with family income situated between four and six times the minimum wage do not migrate to the digital signal is equal to two-thirds - or $67 \%$ - estimated from sample:

$$
\text { Not Migration ratio }\{\mathrm{INCOME}=2\}=\frac{0,67}{1-0,67}=2
$$

The probability that an individual with income above a level, between six and eight times the minimum wage, will not migrate to digital TV drops to $51.4 \%$, consistent with this inference supports the hypothesis:

$$
\pi[\mathrm{TVD}]_{\mathrm{AGE}=3}=\frac{2 x 0,529}{1+2 \times 0,529}=0,5140
$$

The other hypothesis, $\mathrm{H} 2, \mathrm{H} 3, \mathrm{H} 5, \mathrm{H} 7$ e $\mathrm{H} 8$ were not confirmed.

\subsection{STATISTICAL SIGNIFICANCE}

Initially we adopted the test of goodness of fit from Hosmer et Lemeshow (2000). In this case, the value for the chi-square should be small enough so that, at the borderline level of 0.05 , is not rejected the assumption that the predicted values are close to the observed values. Table 2 shows that, in the second step of the stepwise regression, the value obtained for the chi-square dropped to 12.372 , with a level of significance calculated 0.089 , still above 0.05 , revealing the smooth adjustment of the model. In the next step, the chi-square decreased to 6.472 and increased to 0.595 significance, confirming the adequacy of the model. Table 3 of contingency by Hosmer et Lemeshow (2000) compares sets of observations similar to their estimates. Expected values close to those observed indicate good quality adjustment. Any discrepancies are identified for isolated sets. The sets 4, 5, 6 and 9 showed misclassification to a single subject. The set 8 showed the lowest quality, with two misclassifications. In general, the goodness fit was considered satisfactory, with a total of 76 hits in 82 chances. Table 4 presents the statistics of -2 log likelihood and pseudo-R2 for each step. The pseudo- $\mathrm{R}^{2}$ based on the likelihood between the proposed model and the null model without predictors variables. When the value of the pseudo-R2 from Nagelkerke approaches from unity, the set of predictor variables of the model increases its degree of explanation of variable response. It is observed that this increased as that in the first step, with the inclusion of the variable VALS2 [1], the proposed model explained $51.9 \%$ of the variation, and in the third and last step, this level rose to $70.7 \%$, indicating good quality specification. Analyzing the change in the statistical -2 log likelihood initially checking is recommended values from chi-square test Omnibus, since these values calculated for each step reflect the "gain" due to the insertion of the variable at that step (see Table 5). So we can affirm that "gain" arising from the introduction of VALS2 [1] in step 1 was represented by the significant value of the chi-square equal to 38.292 , observable in the model resulting total for a single predictor variable explaining the variation of the response variable.

In step 2, with the introduction of the age variable, the "gain" significant was equal to 12.593 , bringing thus the chi-square model to 50.885 (sum of the "gains" with the introduction of both variables). Finally, the inclusion of the income variable provided an increase in the chi-square 7.206, further distinguishing it from the null model (without predictors). Table 6 shows the effect of complementarity in explaining the response variable from the action of the covariance of the predictor variables. With the withdrawal of VALS2 [1] in step 1, the model "loses" 38.292 in units of chi-square, this time specifying which refers to the situation of the null model. In step 3, the "loss" caused by the withdrawal of the same variable is lower: 8.474 . It occurs because much of the explanation of the model is supported by the other variables included until this step - in this case, age and income - which assist in the specification of the model as a whole. Moreover, it is observed that the presence of the age variable in the final model resulted in the highest "gain" in terms of explanation, which, from the perspective of adherence represents a greater distance from the null model. Table 7 provides a comparative indication between values predicted by the model and observed from the sample. The objective of this phase is to evaluate the 
predictive ability of hits from the classification table. We tested both models: the resulting observations from 82 randomly selected - which served as the basis for the binary logistic regression model - and one that includes the 39 nonselected observations.

Table 2 - Hosmer and Lemeshow (2000)test of adjustment goodness

\begin{tabular}{|c|c|c|c|}
\hline Step & Chi-square & $\begin{array}{c}\text { Degrees of } \\
\text { freedom }\end{array}$ & Significance \\
\hline 1 & 24,606 & 6 & 0,000 \\
\hline 2 & 12,372 & 7 & 0,089 \\
\hline 3 & 6,472 & 8 & 0,595 \\
\hline
\end{tabular}

Source: Authors

Table 3 -Hosmer e Lemeshow (2000) table of contingence for step 3

\begin{tabular}{|c|c|c|c|c|c|}
\hline \multirow{2}{*}{ Group } & \multicolumn{2}{|c|}{ TVD $=0$} & \multicolumn{2}{c|}{ TVD $=1$} & \\
\cline { 2 - 5 } & Observed & Expected & Observed & Expected & Total \\
\hline 1 & 0 & 0,018 & 8 & 7,982 & 8 \\
\hline 2 & 0 & 0,076 & 7 & 6,924 & 7 \\
\hline 3 & 0 & 0,175 & 9 & 8,825 & 9 \\
\hline 4 & 1 & 0,343 & 8 & 8,657 & 9 \\
\hline 5 & 0 & 0,554 & 8 & 7,446 & 8 \\
\hline 6 & 3 & 1,736 & 5 & 6,264 & 8 \\
\hline 7 & 3 & 3,014 & 4 & 3,986 & 7 \\
\hline 8 & 3 & 5,093 & 6 & 3,907 & 9 \\
\hline 9 & 8 & 7,060 & 0 & 0,940 & 8 \\
\hline 10 & 9 & 8,931 & 0 & 0,069 & 9 \\
\hline
\end{tabular}

Source: Authors

Table 4 - Summary of tests-2 Log likelihood and pseudo- $\mathbf{R}^{2}$

\begin{tabular}{|c|c|c|c|}
\hline Step & $\begin{array}{c}-2 \text { Log } \\
\text { likelihood }\end{array}$ & $\begin{array}{c}\text { Pseudo-R }{ }^{2} \text { Cox and } \\
\text { Snell }\end{array}$ & $\begin{array}{c}\text { Pseudo- } \\
\mathrm{R}^{2} \text { Nagelkerke }\end{array}$ \\
\hline 1 & 65,628 & 0,373 & 0,519 \\
\hline 2 & 53,035 & 0,462 & 0,644 \\
\hline 3 & 45,829 & 0,508 & 0,707 \\
\hline
\end{tabular}

Source: Authors

Table 5 - Test Omnibus for the coefficients of the model

\begin{tabular}{|c|c|c|c|}
\hline Step & Chi-square & g.l. & Significance \\
\hline 1-Step & 38,292 & 1 & 0,000 \\
\hline Block & 38,292 & 1 & 0,000 \\
\hline Modeo & 38,292 & 1 & 0,000 \\
\hline 2 - Step & 12,593 & 1 & 0,000 \\
Block & 50,885 & 2 & 0,000 \\
Model & 50,885 & 2 & 0000 \\
\hline 3- Step & 7,206 & 1 & 0,007 \\
Block & 58,091 & 3 & 0,000 \\
Model & 58,091 & 3 & 0,000 \\
\hline
\end{tabular}

Source: Authors
Table 6 - Model of variable removal

\begin{tabular}{|c|c|c|c|c|c|}
\hline Passo & Variable & $\begin{array}{c}\text { Log } \\
\text { likelihood }\end{array}$ & $\begin{array}{c}-2 \text { Log } \\
\text { likelihood }\end{array}$ & $\begin{array}{c}\text { Degrees of } \\
\text { freedom }\end{array}$ & Sig. \\
\hline 1 & VALS2[1] & $-51,960$ & 38,292 & 1 & 0,000 \\
\hline 2 & VALS2[1] & $-49,459$ & 45,882 & 1 & 0,000 \\
\hline & AGE & $-32,814$ & 12,593 & 1 & 0,000 \\
\hline 3 & VALS2[1] & $-27,152$ & 8,474 & 1 & 0,004 \\
\hline & AGE & $-31,122$ & 16,416 & 1 & 0,000 \\
\hline & INCOME & $-26,518$ & 7,206 & 1 & 0,007 \\
\hline
\end{tabular}

Source: Authors

Table 7 - Classification table

\begin{tabular}{|l|c|c|c|c|}
\hline \multicolumn{2}{|l|}{ Step } & 0 & 1 & Correct \\
\hline 1 & 0 & 12 & 15 & 55,6 \\
\hline Total percentage & 1 & 55 & 0 & 100 \\
\hline 2 & 0 & 6 & 21 & 77,8 \\
\hline & 1 & 53 & 2 & 96,4 \\
\hline Total percentage & & & & 90,2 \\
\hline 3 & 0 & 7 & 20 & 74,1 \\
\hline & 1 & 49 & 6 & 89,1 \\
\hline Total percentage & & & & 84,1 \\
\hline
\end{tabular}

In the selected sample, given the characteristics of the predictor variables, the degree of correct attitude favorable to the first step, only with the participation of VALS2 [1], was $100 \%$. However, scores for the unfavorable attitude resulted in $55.6 \%$ only. In the second step, after the inclusion of the Age variable, the hits became more distributed, equal to $96.4 \%$ and $77.8 \%$ for the attitude favorable and unfavorable, respectively. In the third and final step, after the inclusion of Income, the ratio of hits to the favorable attitude was equal to $89.1 \%$, or 49 of 55 possible. To the unfavorable attitude this result fell to $74.1 \%, 20$ out of the 27 possible. The degree of accuracy for the sample taken at random with the inclusion of three predictor variables resulted equal to $84.1 \%$. To test the accuracy of the model shown in the classification table uses the statistic Q Press (Hair et al, 2005), whose formula has the following representation:

$\mathrm{Q}[$ Press $]=\frac{\left[N-(n \cdot K]^{2}\right.}{N(K-1)}$

"N" is the sample size, 82 observations;

" $n$ " is the total number of hits, $49+20=69$;

" $\mathrm{K}$ " is the groups number, in the case of two possibilities.

So, $Q[$ Press $]=38,24$. 
Comparing the calculated value of $Q$ [Press] equal to 38.24 with minimum of 6.63 for the chi-square test, the significance level equal to 0.01 , it is observed that the model seems to have a great performance in predicting propensities of migration, especially the subjects that have identifiable profile positioning favorable to migration.

\subsection{TEST OF RESIDUE AND INFLUENCE}

If, on the one hand, among the eighty-two predictions made by the model with the selected sample, thirteen resulted in incorrect, the question is to know which of these subjects showed residues whose differences between estimated and observed values were considered statistically significant. The standardization of residues ensures that they present the mean as zero value and unit standard deviation, being comparable. As they follow a " $\mathrm{t}$ " distribution, the bilateral reference limit obtained from the table with a significance level of $5 \%$ is 1.96 . The standardization of residues ensures that they present value of zero mean and unit standard deviation, being comparable. As follow a distribution " $t$ ", the reference limits obtained bilateral table with a significance level of $5 \%$ is 1.96 . So it is possible see in Figure 2, which have occurred three observations whose

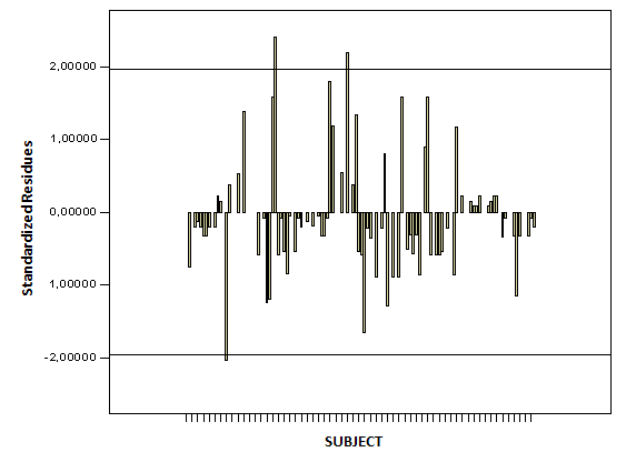

Figure 2 - Standardized residues

Source: Authors

\subsection{Validation}

The validation sample was used to check the consistency of the model to make reliable predictions for DTV. In this case, the model parameters estimated were applied on the observations of the predictor variables in this sample. Then logit scores were obtained and calculated the equation of inequality:

$$
p=\frac{e^{\log \ddot{t}}}{1+e^{\log t}}
$$

values extrapolated the critical limit identified in the order, such as 15, 32 and 57, whose values are -2.03, 2.41 and 2.19. The Cook distance, meanwhile, deals with the influence that particular subject has on the fit of the model versus its distance with the other subjects of the sample, called leverage (Hair et al, 2005, p.192). Those whose values for Cook's distance proved greater than 1.0 undermined the predictive ability of the model.

Figure 3 shows that no subject was above this upper limit. Although outliers were identified by testing the standardized residuals since it did not occur to the same conclusion test distance Cook, we chose to not extract any subject sample, keeping the model binary logistic regression estimated initially. The Cook distance, meanwhile, deals with the influence that a particular subject has on the fit of the model versus its distance to the other subjects of the sample, called leverage (Hair et al, 2005, p.192). Those whose values for Cook distance proved greater than 1.0 have undermined the predictive ability of the model. Figure 3 shows that no subject was above this upper limit. Although outliers were identified by testing the standardized residuals since the same did not occur on Cook distance test, we chose not to extract any subject from the sample, keeping thus the model binary logistic regression estimated initially.

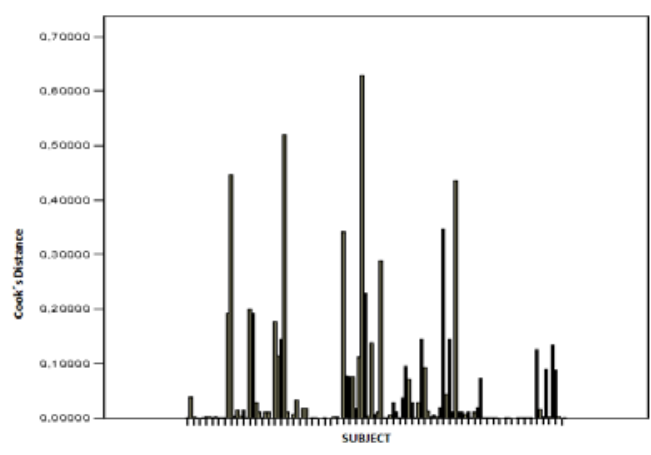

Figure 3 - Cook's Distance

Source: Authors

Values of " $p$ " below 0.5 were considered favorable to the propensity to migrate to digital TV and vice versa. Table 8 demonstrates that, for the validation sample, the degree of correct for the bias favorable for digital TV migration was $94.7 \%$, or 18 in 19 as possible. To negative bias, the degree of correct significantly reduced to $65 \%$, or 13 in 20 as possible. The total percentage of correct answers for the second sample was $79.5 \%$. The comparable value of $Q$ [Press] to 39 observations with 31 hits and two groups was equal to 13.564. Therefore, higher than the chi-square lower limit tabulated of 6.63 , validating the model. 
Brazilian Journal of Operations \& Production Management

Volume 12, Número 2, 2015, pp. 258-269

DOI: 10.14488/BJOPM.2015.v12.n2.a6

Table 8-Classification table for the validation sample

\begin{tabular}{|l|c|c|c|c|}
\hline Step & & 0 & 1 & Correto \\
\hline 1 & 0 & 11 & 9 & 45,0 \\
\hline Total percentage & 1 & 19 & 0 & 100 \\
\hline 2 & 0 & 6 & 14 & 71,8 \\
\hline & 1 & 18 & 1 & 94,7 \\
\hline Total percentage & & & & 82,1 \\
\hline 3 & 0 & 7 & 13 & 65,0 \\
\hline & 1 & 18 & 1 & 94,7 \\
\hline Total percentage & & & & 79,5 \\
\hline
\end{tabular}

Source: Authors

\section{MARKETING IMPLICATIONS}

From the analysis of the sample was possible to observe the performance of this methodology for discriminating between groups of subjects from their sociodemographic and psychographic. A property of the technique refers to the ease of application of tool VALS-2. Although it contains thirty-nine questions - which, added to other questions in the questionnaire, the interview process became extensive in the opinion of some interviewees - their tabulation is quick and to obtain results through the website of SRI is immediate. The classification VALS-2, have been considered relevant to the determination of the segment of the population that wanted to migrate to digital TV, shows the possibility of its application as a research tool Marketing in survey the profile of population segments minded to consume particular product or service.

The results evidenced the indifference of categorical variable Gender to explain the attitude to new technology. This eliminates expectations of conservatism or transfer from role maker to man or woman. So it is not characterized as digital TV products in the category of those whose involvement in the buying process is specific to a particular genre, such as the choice of products on grocery shopping, determined mainly by females. The fact that the Lifestyles second level has not presented significant relationship stems from the inherent characteristic of technical VALS. The first level is the dominant way in which the subject is a fact of life, while the second level is complementary, emphasizing a behavioral bias (SRI, 2007). This characteristic of the second order, when viewed in isolation, does not provide a coherent relationship with the response variable. However, if combined properly with the Lifestyle first level, could result in a relevant contribution. To allow considerate of variable resulting from the combination of both levels ordinal scale, a hierarchical analysis of the 64 segments resulting from the processing would be necessary.

The Economics is not confirmed significant contribution to the model, presenting a strong negative correlation with the level of family income. Arising out of multicollinearity, both high score were caused by the presence of high covariance, and just only when the second was selected by stepwise procedure, its absence in the next step would cause a significant reduction in the contribution of the former.

Regarding the Level of Instruction, different from authors mentioned before, the low significance of this variable to explain the model is probably due to a selection bias in the sample. As several interviewees were part of the faculty and students of a university, despite high academic titles they had no necessarily reasonable knowledge of the benefits of digital television, nor afford to bear the cost of the transition.

Finally, the elimination of the variable knowledge of digital TV probably denotes that, precisely because they have not yet enough information and judgment about this technology, some respondents expressed their reticent for not realizing some apparent advantage between cost and benefit comes from migration.

For selected variables, the VALS first level confirmation indicates that subjects with Lifestyle more innovative and affluent have better chances to migrate. For the Ages, young people are naturally more flexible when it comes to migrating to an innovative product, since, by witnessing the successive advances in technology in the areas of micro computing and telecommunications, are less reactive to continue transitioning to new technologies. Finally, the Family Income shows that the costs associated with migration, such as the possession of television would broadcast a digital signal, to the time of the survey manifested also itself as a constraint on the decision to join the new technology. After analysis, it was observed that among the eight variables tested to compose a basis of segmentation migration to digital TV, only three were confirmed as effective predictors in the characterization of potential users.

With regard to specific objectives, is possible to see that other bases instead the traditional segmentation could be used to identify potential users of digital TV.

\section{FINAL CONSIDERATIONS}

Performed when the start of the offering digital TV via DTH transmission system called, the field survey of this research revealed that: a) There was no Gender discrimination among adopters of digital TV. We conclude that, on this point, the profile could not be constituted in a difference between men or women; b) With respect to Age, concentrations have occurred in certain psychographic segments. All those who are aged between 30 and 34 years were classified as "strivers". Respondents aged 35 to 54 were distributed indiscriminately among all segments. The other, aged 55, is positioned in the most extreme of "innovators" and "survivors"; c) About Economics, the results confirmed 
Brazilian Journal of Operations \& Production Management

Volume 12, Número 2, 2015, pp. 258-269

DOI: 10.14488/BJOPM.2015.v12.n2.a6

the expectations from method VALS-2. The "innovators", the "achievers" and "experiencers" put together people of higher profile. In this respect, a small exception was observed in the segment of "thinkers" whose classification showed no clear distinction between the economic status of respondents; d) Those with higher levels of Education concentrated on segments of "innovators" and "experiencers".

Such situations explain in part the observed division between segments VALS- 2 in Figure 4: those who declared to intend to migrate to digital television and those who have not. A darker shade distinguishes adopters segment, characterized by presenting respondents whose psychographic profile is aligned with higher income classes and the search for status.

Several constraints delimit the scope of this research. First of all, it was led from a limited population, composed of students and professors who worked on two campuses located in the cities of Rio de Janeiro and Niteroi, Brazil. The sample of 121 respondents, although representative for an academic work, becomes insignificant when compared to the survey conducted by SRI in the first application of VALS in 1980 , when 1,635 people were interviewed, or even in 1982 , when 12,438 subjects were interviewed. Note the importance of broadening the scope of sample, in the aspects of the scope and size, as well as in the stratified random selection, not conducted for this work, so that the results can definitely be considered valid.

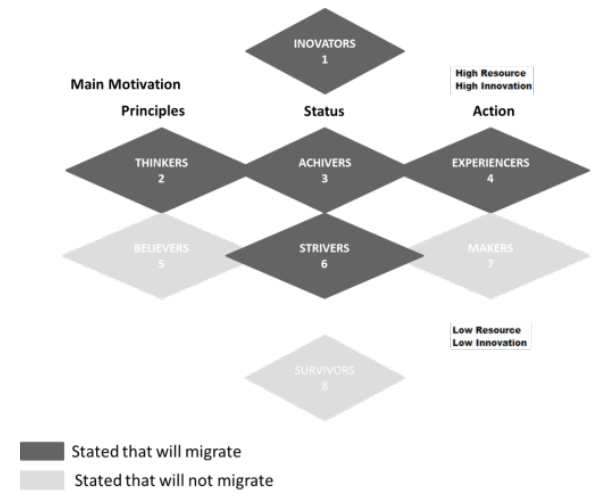

Figure 4-Segmentation as for the intention to migrate to digital TV Source: Authors

Another limitation refers to the adaptation of the technique VALS-2, originally used to determine the psychographic characteristics observed in American society. Furthermore, the definition of the attributes of digital TV, as well as the costs of migration, were limited to those found in the theoretical framework.

On the other hand it is relevant to have treated research focused on sociodemographic and psychographic variables that influence the adoption of technology by consumers conducted ex ante but their deployment - i.e., when the consequences are not yet fully assimilated by the interviewees. To find a priori understand consumer reactions when it comes to launching innovations is undoubtedly a wise step to minimizing corporate risk.

Finally, some findings may serve as a benchmark for future studies that seek, for example, to measure the effects caused by the increase of knowledge resulting from information about digital TV. Other research also could combine the dependent variables VALS- 2 first level and second level VALS-2, to be transformed into a single independent variable.

\section{REFERENCES}

ABEP. (2003). Associação Brasileira de Empresas de Pesquisa. Disponível em: www.abep.com.br Dados com base no Levantamento Sócio Econômico 2003. Acessado em 05/07/2007.

ATKIN, D. et al. (1998)Understanding Internet Adoption as Telecommunications Behavior.Journal of Broadcasting and Electronic Media, v.42, n.4, p.475-490.

ATKIN, D. et al. (2003) Predictors of Audience Interest in Adopting Digital Television.Journal of Media Economics, v.16, n.3, July, p.159-173.

BROWN, A. (2004) Implications for Commercial Broadcasters. In: BROWN, A.; PICARD, R.G. Digital Terrestrial Television in Europe. Londres: Routledge, p.85-100.

CAUBERGHE, V. and PELSMACKER, P. (2006). Opportunities and Thresholds for Advertising on Interactive Digital TV: a view from advertising professionals. Journal of Interactive Advertising, v.7, n.1, Fall, p.25-40.

CHORIANOPOULOS, K. (2008) Personalized and Mobile Digital TV Applications. Multimed Tools Application, v.36, p.1-10.

CLARK, R.A. and GOLDSMITH, R.E. (2006) Interperson Influenced and Consumer Innovativeness. International Journal of Consumer Studies, v.30, n.1, p.34-43.

DUPAGNE, M. (2006) Predictors of Consumer Digital Television Awareness in the United States.Communication Research Reports, v.23, n.2, July, p.119-128.

EL-HADDAD, A. and ALMAHMEED, M. (1992) ATM Banking Behavior in Kuwait: a consumer survey. International Journal of Bank Marketing, v.10, n.3, p.250-282.

GAUVIN, S. and SINHA, R.K. (1993) Innovativeness of Industrial Organizations: a two-stage model of adoption. International Journal of Research in Marketing, v.10, n.2, p.165-184.

GILLY, M.C. and ZEITHAML, V. (1985) The Elderly Consumer and Adoption of Technologies. Journal of 
ConsumerResearch, v.12, Dec, p.353-357.

GOUVEIA, V.V. et al. (2001). A Estrutura e o Conteúdo Universais dos Valores Humanos: análise fatorial confirmatória da tipologia de Schwartz. Estudos de Psicologia, v.6, n.2, p.133-142.

GUPTA, S. and JAIN, D.C.; SAWHNEY, M.S. (1999) Modeling the Evolution of Markets with Indirect Network Externalities: an application to digital television. Marketing Science, v.18, n.3, p.396-416.

HOINEFF, N. (1991) TV em Expansão.Rio de Janeiro: Record.

HOLMAN, R. (1984) A Values and Lifestyles Perspective on Human Behavior.In Personal Values and Consumer Psychology - Pitts \& Woodside.

HOMER, P.M. and KAHLE, L.R.A (1998) Structural Equation Test of the Value-Attitude-Behavior Hierarchy.Journal of Personality and Social Psychology, v.54, p.638-646.

HOSMER, D. and LEMESHOW, S. (2000) Applied Logistic Regression. New York :Wiley

IBGE (2005). Pesquisa Nacional por Amostra de Domicílios. Acessado em 05 de julho de 2007 e disponível em www.ibge. gov.br/home/estatistica/populacao/trabalhoerendimento/ pnad2005/default.htm.

JENSEN, J.F. (2004) Interactive Content, Applications and Services. In: BROWN, A.; PICARD, R.G. (2004) Digital Terrestrial Television in Europe. Londres: Routledge, p.85100.

KAHLE, L.R. (1983) Social Values and Social Changes: adaptation to life in America.New York: Praeger.

KAHLE, L.R. (1995a) Observations: the role-relaxed consumers, a trend of the nineties. Journal of Advertising Research, v.35, p.66-71.

KAHLE, L.R. (1995b) Observations: the role-relaxed consumers, empirical evidence. Journal of Advertising Research, v.35, p.59-62.

KAHLE, L.R. et al. (1986) Alternative Measurement Approaches to Consumer Values: the list of values (LOV) and values and life style. Journal of Consumer Research, v.13, p. 405-409.

KAMAMURA, W. and NOVAK, T. (1991) Value-System Segmentation: exploring the meaning of LOV. Journal of Consumer Research, v.19, p.119-132.

LA ROSE, R. and ATKIN, D. (1988) Satisfaction, Demographic and Media Environment Predictors of Cable Subscription. Journal of Broadcasting and Electronic Media, v.32, n.4, p.403-413.
LEE, E.J. et al. (2003) A Two-Step Estimation of Consumer Adoption of Technology Based Service Innovations. The Journal of Consumer Affairs, v.37, n.2, p.256-282.

LEUNG, L. (1998) Lifestyles and the Use of New Media Technology in Urban China.Telecommunications Policy, v.22, n.9, p.781-790.

MALIK, M. (2008) The Challenge of Digital Migration. Business World. Thursday, June 19.

MAREZ, L. et al. (2007) Adopter Segments, Adoption Determinants and Mobile Marketing.Journal of Targeting, Measurement and Analysis for Marketing, v.16, n.1, p.78-95.

MATHUR, A. et al. (2006) Life-Changing Events and Marketing Opportunities. Journal of Targeting, Measurement and Analysis of Marketing, v.14, n.2, p.115-128.

MAVRI, M. and IOANNOU, G. (2006) Consumers' Perspectives on Online Banking Services.International Journal of Consumer Studies, v.30, n.6, Nov, p.552-560.

MONTAGUTI, E. et al. (2002) Entry Strategy for Radical Product Innovations: a conceptual model and propositional inventory. International Journal of Research in Marketing v.19, n.1, p.21-42.

MOREAU, C.P. et al. (2001) Entrenched Knowledge Structures and Consumer Response to New Products. Journal of Marketing Research.v.28, Feb, p.14-29.

MOWEN, J. and MINOR, M. (2003) Comportamento do Consumidor. São Paulo: Pearson Prentice Hall.

PICARD, R.G. (2004) A Consumer Perspective on Digital Terrestrial and Interactive Television. In: BROWN, A.; PICARD, R.G. Digital Terrestrial Television in Europe. Londres: Routledge, p.133-150.

PORTO, J.B. and TAMAYO, A. (2007) Estrutura dos Valores Pessoais: a relação entre valores gerais e laborais. Psicologia: Teoria e Pesquisa. v.23, n.1, p.63-70.

ROKEACH, M. J. (1973) The Nature of Human Value. New York: Free Press, 1973.

SCHWARTZ, S.H. (1994) Are there universal aspects in the structure and contents of human values? Journal of Social Issues, v.50, p.19-45.

SHETH, J. et al. (2001) Comportamento do Cliente: indo além do comportamento do consumidor. São Paulo: Atlas.

SIMCOCK, P. et al. (2006) Age, Perceived Risk and Satisfaction in Consumer Decision Making: a review and extension. Journal of Marketing Management, v.22, p.355377.

SOLOMON, M. (1998) Consumer Behavior: buying, having and being $-4^{\text {th }}$ ed. Upper Saddle River, New Jersey. 
SRI Consulting Business Intelligence (2007).VALS Survey. Acessado em 03/10/2007. Disponível em: http://www.sricbi.com/VALS.

STRUTTON, H.D. et al. (1994) An Applied Investigation of Rogers and Shoemaker Perceived Innovation Attribute Tipology when Marketing to Elderly Consumers. Journal of Applied Business Research, v.10, n.1, p.118-131.

TAMAYO, A. (2007) Hierarquia de Valores Transculturais e Brasileiros. Psicologia: teoria e pesquisa. v.23, n.1, p.7-15.

VEIGA-NETO, A. (1997) Um Estudo Comparativo de Formas de Segmentação de Mercado: uma Comparação entre VALS2 e Segmentação por Variáveis Demográficas com Estudantes Universitários. Revista de AdministraçãoContemporânea, v.1 n.1, Janeiro; Abril.

WAARTS, E. et al. (2002) The Dynamics of Factors Affecting the Adoption of Innovations.The Journal of Product Innovation Management, v.19, n.6, p.412-423.

WADE, N. and MCKECHNIE, S.A. (1999) The Impact of Digital Television: will it change our shopping habits? Journal of Marketing Communications, v.5, n.2, June, p.71-84.

ZEITHAML, V. and GILLY, M. (1987) Characteristics Affecting the Acceptance of Retailing Technologies: a comparison of elderly and nonelderly consumers. Journal of Retailing.v.63, n.1, p.49-68. 